\title{
AMBIENTE DA REGIÃO NORDESTE: OS EFEITOS NEGATIVOS DA DESTERRITORIALIZAÇÃO EM MATO GROSSO DO SUL
}

\author{
Paola Bueno Quirino ${ }^{1}$
}

Valter Guimarães ${ }^{2}$

\begin{abstract}
RESUMO
O interesse em propor estudar a Região Nordeste do Estado de Mato Grosso do Sul nasceu de visita ao mais novo município Paraíso das Águas objetivando em contribuir com reflexões a respeito do desenvolvimento local, visando a Política de Desenvolvimento Regional interligando com a Política de Sustentabilidade Ambiental. Esta proposta de trabalho leva de forma geral a investigar no campo de estudo da Geografia as consequências do desenvolvimento econômico sobre as questões da Dimensão Ambiental constante na carteira de projetos a longo prazo, na região de estudo, executados ou em execução com previsão até 2020. A pesquisa poderá contribuir nas questões da produção de indicadores ambientais, devido ao intenso processo produtivo agrícola e oferta de produtos turísticos produzidos na região. Diante dos efeitos da desterritorialização ocorridas na área de estudo, a Região Nordeste, parece ter sido a que mais sofreu com os avanços de usos e ocupação do solo como a pecuária intensiva e o de confinamento, bem como a da agricultura mecanizada de mono e policultivo que são bastantes expressivas na paisagem rural. Portanto, com essas ações de efeitos impactantes de fragmentação do espaço, novos cénarios serão objeto de correlação com a implementação das carteiras de projetos que possam ter contribuição eficaz nos destinos de uma dimensão ambiental harmoniosa.
\end{abstract}

PALAVRAS-CHAVE: Desterritorialização. Produtividade Rural. Dimensão Ambiental.

\section{NORTHEAST REGION OF ENVIRONMENT: THE NEGATIVE EFFECTS OF DETERRITORIALIZATION IN MATO GROSSO}

\section{SUL}

\section{ABSTRACT}

The interest in offering study the northeastern state of Mato Grosso do Sul Region born visit to the new municipality of Paradise Waters aiming to contribute to reflections on the site development for the Regional Development Policy connecting with the Sustainability Policy environmental. This work proposal leads in general to investigate the Geography field of study the impact of economic

\footnotetext{
${ }^{1}$ Mestranda em Geografia, UFMS/CPAQ. pa_facul2011@hotmail.com

2 Doutor em Geografia, Professor Associado IV-UFMS/CPAQ. vgeovalter@gmail.com
} 
development on the issues of constant environmental dimension in long-term project portfolio, in the study region, executed or running with forecast 2020. the research could help in matters of production of environmental indicators, due to the intense agricultural production process and supply of tourist products of the region. Facing the effects of dispossession occurred in the study area, the Northeast, seems to have been the hardest hit with the advances of uses and land use as intensive farming and the confinement and the mechanized farming of mono and polyculture that are quite expressive in the countryside. Therefore, with these actions of striking effects of space fragmentation, new scenarios will be correlation object to the implementation of project portfolios that may have effective contribution in the destinies of a harmonious environmental dimension.

\section{MEDIO AMBIENTE DE LA REGIÓN NORDESTE: LOS EFECTOS NEGATIVOS DE LA DESTERRITORIALIZACIÓN EN MATO GROSSO DO SUL}

RESUMEN: El interés en proponer estudiar la Región Nordeste del Estado de Mato Grosso do Sul, nació de visitar al nuevo municipio Paraíso das Águas teniendo en contribuir con reflexiones sobre el desarrollo local, con vistas la politica de dessarrolo regional con la politica de sostenibilidad ambiental. Este trabajo proponer conduce por lo general a investigar el campo de estudio de la geografia las consecuencias del desarrollo econômico sobre las cuestiones de dimensión ambiental constante en la carteira de proyectos a largo plazo en la región de estudio, ejecutado o en ejecución programada hasta 2020. La investigación podría ayudar en los problemas de producción de indicadores ambientales, debido al processo de producción agrícola intensa y la oferta de productos turísticos de la región. Ante los efectos de la desterritorialización ocurridas en el área de estudio, el Región Nordeste parece haber sido el más afectado por los avances de los usos y ocupación del suelo como la ganadería intensiva y el de confinamiento así como de la agricultura mecanizada de mono y policultivo que son bastante expresivas en la paisaje rural. Por tanto, con estas acciones efectos de la fragmentación del espacio impactar, nuevos escenarios serán sujetos de correlación con la ejecución de la cartera de proyectos que puedan tener contribución efectiva los destinos de una dimensión ambiental armonioso.

PALABRAS-CLAVE: Desterritorialización. Productividad Rural. Dimensión ambiental.

\section{INTRODUÇÃO}

Conforme Santos e Silveira (2001), o espaço é um conjunto indissociável de sistemas de objetos e sistemas de ações. Esses autores definem o território como um objeto de divisões de trabalho superpostas e que cada empresa produz a sua própria divisão do trabalho, expandindo-se posteriormente. Este crescimento é marcado pela redistribuição e pelo uso diferencial do território. Segundo Baggio (2002), a perspectiva do fenômeno da globalização é o do globalizar de forma 
fragmentada. Se ela promove articulação, interdepência e integração entre mercados, países, regiões, lugares, certamente também gerará fragmentações de territórios e da sociedade, na qual afetaria o meio fisíco trazendo grandes impactos na natureza.

Egler (1995), afirma que o território pressupõe da existência de relações de poder, sejam elas jurídicas, políticas ou econômicas. Isto é evidente na Política de Desenvolvimento Regional de Mato Grosso do Sul que reflete um conjunto de informações formais ou informais, gerenciados pelas instituições públicas governamentais, com abrangência e lou competências em níveis federal, estadual e municipal; tendo período de vigência além do mandato de seus governantes, com duração de médio e longo prazo.

\begin{abstract}
Isto parece estar presente quando sabe-se dos significativos avanços no uso da terra fértil em direção à divisa com o Estado de Goiás. O interesse em propor estudar a Região Nordeste do Estado de Mato Grosso do Sul nasceu de visita ao mais novo município Paraíso das Águas (que surgiu a partir da herança como distrito de Costa Rica), em contribuir com reflexões a respeito do desenvolvimento local, visando a Política de Desenvolvimento Regional interligada com a Política de sustentabilidade Ambiental. Da visita a este município conseguiu-se produzir artigo científico dando ênfase à problemática da produção de lixo (QUIRINO et al, 2013).
\end{abstract}

Esta proposta de trabalho leva de forma geral a investigar no campo de estudo da Geografia as consequências do desenvolvimento econômico sobre a dimensão ambiental constante na carteira de projetos a longo prazo, da região de estudo, executados ou em execução com previsão até 2020.

O desenvolvimento desta pesquisa encontra amparo na preocupação do governo estadual manisfetada no Plano de Desenvolvimento Regional, devido às transformações que houveram no território sul-mato-grossense desde a sua criação com o desmembramento de terras que redundaram em mais vinte e quatro novos municípios, deixando a cada um deles a busca de caminhos da sobrevivência sócio, político e econômica. Nesta primeira fase da pesquisa investiga-se o que foi a realidade histórica do território Região Nordeste combinando alguns diagnósticos com os pressupostos da sustentabilidade daquele ambiente.

\title{
2 DESENVOLVIMENTO
}


As peculiaridades da área da pesquisa, Região Nordeste, começam pelo entendimento da dimensão espacial do antigo território de Coxim, posteriormente Camapuã e todo um processo ocorrido recentemente (a partir da década de 1980), com inúmeros desmembramentos de áreas de municípios do então Estado de Mato Grosso, elevando atualmente de 55 para 79 e, na Região Nordeste 4 novos municípios a integram, junto com Camapuã criado em 1948, assim caracterizados (MS/SEMAC, 2013):

- O município de Camapuã nasceu de terras desmembradas de Coxim, deixando de ser distrito em Setembro de 1.948, correspondendo a uma área de 6.229,620 km².

- Criado pela lei $n^{\circ} 768$ Chapadão do Sul tornou-se município a partir de terras desmembradas de Cassilândia, com área territorial de $3.851,000 \mathrm{~km}^{2}$.

- Costa Rica possui uma área de 5.371,801 km², oriunda de terras desmembradas de Camapuã, Cassilândia, Paranaíba, Coxim e Água Clara.

- A partir do desmembramento das terras de Camapuã e Costa Rica foi criado o município de Figueirão. Sua área territorial é de $4.882,873 \mathrm{~km}^{2}$.

- Paraíso das Águas era considerado distrito de Costa Rica até no final de 2012, que recebeu terras dos municípios de Costa Rica, Água Clara e Chapadão do Sul, criando-se o mais novo município do Estado a partir de $1^{\circ}$ de Janeiro de 2013. Divide limites com os municípios de: Camapuã, Água Clara, Chapadão do Sul e Costa Rica. Sua área territorial é de $5.032,469 \mathrm{~km}^{2}$.

A região da pesquisa com seus municípios integrantes está representada na figura 1, mapeamento fornecido pelo IBGE, 2013, adaptando-se nele a linha limítrofe do perímetro do espaço em estudo. 


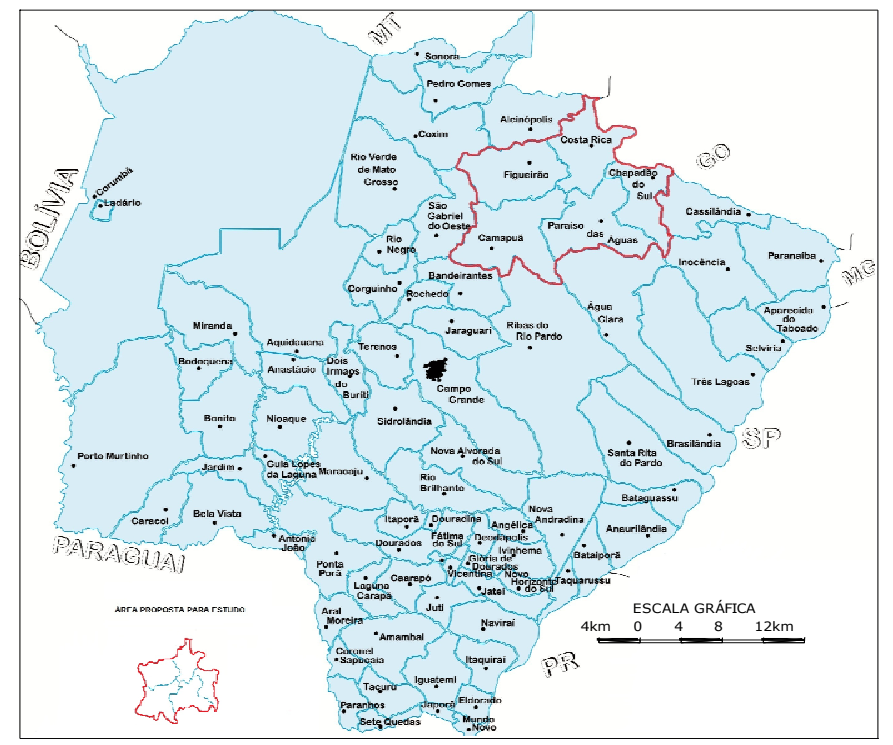

Figura 1. Mapa Político do Estado de Mato Grosso do Sul. Área proposta para estudo. Fonte: IBGE/Gov.MS. Adaptado: Quirino, 2013.

\subsection{Relato Histórico Regional Anterior à criação do Estado de Mato Grosso do Sul.}

Buscando entender os momentos de ocupação e da expansão do território foi preciso fazer uma busca nas publicações de autores que relatam a história de reorganização do espaço, dando enfoque a questão de uso e ocupação.

Segundo Campestrini e Guimarães (1995), a exploração do antigo território de Mato Grosso, incluindo-se a parcela de Mato Gosso do Sul, iniciou-se com a busca incessante do ouro, através de rotas fluviais, com isso possibilitou o povoamento expandindo-se em toda a região do território brasileiro. Os autores falam também da fazenda Camapuã que foi muito importante para os viajantes, onde eles faziam suas paradas para descansar e reabastecer sua mercadorias, enfrentando perigos até nas travessias devido a fortes correntezas dos rios e eram perseguidos por índios que não Ihes poupavam a vida. Com a fase de exaustão do ouro no governo de Alburquerque, a fazenda Camapuã entrou em decadência em 1789, ficando abandonada por falta de viajantes que nela abasteciam com isso perdeu sua importância por determinado período. 
Para Corrêa Fillho (1934), a história de ocupação teve início com o avanço dos paulistas em todo o território do Estado de Mato Grosso, que vieram com o interesse de explorar as minas de Cataguazes e outras que existiam no território naquele período.

Barbosa (2002), registra em uns de seus relatos a ocupação do território por Pascoal Moreira Cabral ocorrido em 1718, cuja intenção era aprisionar os índios ocupando as terras de Coxiponés, onde descobriu ouro abundante, junto ao rio Coxipó-Mirim. Com a descoberta de pedras preciosas, foi superada a fase de exploração e escravidão indígena, estabelecendo-se um movimento migratório de aventureiros e comerciantes vindo do litoral para a região das minas. Com isso decididos a valorizar-se a herança recebida, nasceu, em 08 de Abril de 1719, o Arraial da Forquilha na cidade de Cuiabá, iniciando-se a partir daí a corrida do ouro em todo o Estado de Mato Grosso.

\subsection{O Plano de Desenvolvimento Regional para o recém criado Estado de Mato Grosso do Sul.}

O Governo de Mato Grosso do Sul, desde 2002 buscou consolidar planos de Desenvolvimento Regional para melhor compreender as opções estratégicas da visão de futuro para todo o território sul-mato-grossense. Nessa proposta de trabalho nossa região para estudos ambientais congrega municípios das regiões Norte e do Bolsão. Para a Região Norte, foram determinados seis eixos, com ações visando as transformações político-institucionais, sócio-econonômicas, técnico-culturais e físicoambientais, a seguir (MS/IPLAN/UCDB, 2002):

a) Melhoria das ações governamentais e das instituições de planejamento da região;

b) Ampliação e adequação da infra-estrutura econômico-produtiva e incentivo à geração de emprego e renda;

c) Implementação de políticas educacionais voltadas à melhoria da qualidade de vida e cidadania;

d) Diversificação da produção e agregação de valor com uso de produtos regionais e de mão-de-obra familiar;

e) Ordenamento do uso dos solos e dos recursos hídricos; 
f) Valorização dos patrimônios cultural e natural da região.

O Plano de Desenvolvimento Sustentável da Região Norte, com base nessas ações, visa as condições de melhoria de vida para a população local, buscando alternativas de Desenvolvimento Regional como por exemplo na valorização do setor de emprego para geração de renda nas empresas locais. Apresenta também ações de planejamento para melhorar na organização espacial, através de leis que regularizam o uso do solo e os recursos hídricos voltados à preservação desses recursos. Nessa região há que se considerar a existência de territórios municipais relativamente antigos que acabaram contribuindo para o surgimento de novos municípios e em ambas as situações o predomínio da prática da preservação de patrimônios culturais e naturais são fundamentais para o Desenvolvimento Regional, como por exemplo a representação cultural do município de Coxim no contexto histórico brasileiro, bem como do recém criado município de Costa Rica com a diversidade de riquezas naturais.

No Plano Regional de Desenvolvimento Sustentável do Bolsão as opções estratégicas são as seguintes (MS/IPLAN/UNIDERP, 2003):

a) Diversificação e verticalização das cadeias produtivas agrícolas;

b) Fortalecimento do turismo;

c) Infra-estrutura educacional e qualificação;

d) Dinamização social e valorização humana;

e) Recuperação e conservação dos recursos naturais renováveis;

f) Investimentos estruturadores.

O Plano Regional de Desenvolvimento Sustentável do Bolsão está ligado ao reaproveitamento dos recursos naturais disponíveis como por exemplo, os recursos hídricos abundantes naquela região, que servem como meios necessários para a produção agrícola e também a exploração turística. Busca também a regeneração dos recursos degradados e preservação do ambiente, tendo como estrátegia a conscientização da comunidade.

É importante destacar a existência de projetos voltados ao aumento da cadeia produtiva, significando com isso a intensificação do uso do solo e necessidade de qualificação de mão-de-obra especializada. 
Todas as Regiões administrativas do Plano de Desenvolvimento Regional, incluindo-se as do Norte e do Bolsão, quando estudadas e editadas tiveram o agrupamento dos municípios obedecendo denominações geográficas locais ou de regionalização popularizadas.

O foco principal dessa pesquisa têm sido o de entender a previsão da dimensão ambiental que consta no Caderno de Cenários e Estratégias de longo prazo de Mato Grosso do Sul para 2020, propondo-se a opção de Sustentação Ambiental que visa a conservação e recuperação do meio ambiente, tornando a sua exploração sustentável e que dentro dos objetivos estratégicos a longo prazo (2011 2020) é possível destacar os seguintes (MS/SEPLANCT/IPLAN/2003):

a) Tornar-se um Estado modelo de conservação ambiental;

b) Consolidar a consciência e a cultura de preservação e conservação ambiental;

c) Consolidar o modelo de desenvolvimento sustentável;

d) Desenvolver o Ecoturismo com alta qualidade em acordo com os padrões de excelência;

e) Produzir a inserção de produtos ecologicamente corretos no mercado internacional.

A conservação do meio ambiente significa preservar todos os seus componentes em boas condições, ou seja, ecossistemas, comunidades e espécies. Um meio ambiente equilibrado oferece uma grande variedade de serviços ambientais que podem ser consumidos pela população humana (PINHEIRO e KURY, 2008).

Em Tomaz (2010), Cultura de Preservação designa-se da preservação de bens patrimoniais, deve ter por finalidade conservar traços da vida comum, cotidiana, e mostrar como vivia a sociedade em determinada época, pois o que tende a ser conservado sempre será o objeto considerado valioso, seja pelo valor do material de que é composto, seja por uma herança histórica ligada a uma personalidade ilustre e por isso mesmo dominadora.

A conservação de bens patrimoniais deve ter por objeto edificações que tenham um significado coletivo para determinada comunidade, pois se perpetua a memória de uma sociedade preservando-se os espaços utilizados por ela na construção de sua história (TOMAZ, 2010). 


\begin{abstract}
Desenvolvimento Sustentável significa um processo de mudança onde a exploração de recursos, a orientação dos investimentos, os rumos do desenvolvimento ecológico e a mudança institucional estão de acordo com as necessidades das gerações atuais e futuras, dando ênfase num processo de transformação em que as diversas dimensões do desenvolvimento se harmonizam e reforçam o potencial de desenvolvimento presente e futuro (BECKER, 2002).
\end{abstract}

O Ecoturismo está diretamente relacionado com o conceito de turismo sustentável, que utiliza os recursos naturais e culturais de um determinado lugar e contribui para conservá-los. Busca desenvolver o respeito pela natureza por meio do contato com o ambiente natural e promove o bem-estar da população local (BRASIL/MMA/2002).

\begin{abstract}
Ainda não existem métodos comprovados que meçam os impactos ambientais de um produto em relação ao outro. Se o consumidor conscientizado ecologicamente seleciona para aquisição os produtos considerados "verdes", torna-se assim um consumidor ecológico. As empresas que pretendem ou que oferecem produtos ecologicamente corretos alcançarão com estes consumidores uma vantagem competitiva em relação a seus concorrentes que não possuem esta característica (OTTMAN, 1994).
\end{abstract}

Nos conceitos citados acima pensou-se em estudar a relevância de cada um deles destacando a importância em questão de Desenvolvimento Regional territorial na área de estudo (Região Nordeste); o quê os governantes e a sociedade civil estão fazendo para contribuir quando se trata da questão de tornar o Estado um modelo de conservação ambiental em sua política a longo prazo (2011-2020).

A pesquisa poderá contribuir nas questões da produção de indicadores ambientais, devido ao intenso processo produtivo agrícola e oferta de produtos turísticos produzidos na região. Com isso a dimensão ambiental nos levará a seguir a proposição de caminhos de convivência sustentável daqueles ambientes e investigar se isto tem trazido consequências positivas.

O reconhecimento a campo foi iniciado no primeiro semestre desse ano quando fez-se uma visita em cada sede de município, bem como ao longo de rodovias principais foi possível constatar a intensificação da ocupação espacial rural tanto na produção pecuária como e principalmente dos cultivos agrícolas. Nesse último tipo chegou-se ao absurdo da ocupação das faixas marginais entre as rodovias e a cercas das divisas das propriedades numa típica ação de ganância 
produtiva devido aos atraentes preços pagos pelo mercado internacional como foi o caso dos grãos de soja.

\section{CONCLUSÃO}

O Estado de Mato Grosso do Sul corresponde a um total de 79 municípios, sendo 55 herdados do antigo Mato Grosso. Diante dos efeitos da desterritorialização ocorridas na área de estudo, a Região Nordeste, parece ter sido a que mais sofreu com os avanços de usos e ocupação do solo como a pecuária intensiva e a de confinamento, bem como a da agricultura mecanizada de mono e policultivo que são bastantes expressivas na paisagem. A Região Nordeste é totalmente voltada as atividades econômicas e isso tem gerado problemas de ordem ambiental como o do desmatamento acerelado.

O empobrecimento dos solos e o desequilíbrio ecológico são uma perda inestimável da biodiversidade, ocasionando também erosões, devido à maior exposição do solo à água da chuva. Ainda a alteração do curso regular das correntes de águas fluviais, construção de diques e pontes, quase sempre trazem como consequências as inundações e o assoreamento de canais. Portanto, com essas ações de efeitos impactantes de fragmentação do espaço, novos cénarios serão objeto de correlação com a implementação das carteiras de projetos que possam ter contribuição eficaz nos destinos de uma dimensão ambiental harmoniosa.

\section{REFERÊNCIAS}

BAGGIO, U. C. Considerações sobre a reestrutura econômica global e seus impactos sobre o território. Revista Geousp-Espaço e tempo, São Paulo, n.12, 2002.

BARBOSA, E. F. da F. de M. Evolução Histórica da Ocupação do Município de Camapuã e do Distrito de Pontinha do Coxo-MS. Revista Pantaneira, Aquidauana, v 3, p 27-33, 2002.

BECKER, B. K. A (des) ordem global, o desenvolvimento sustentável e a Amazônia. In: Becker, et al, (Org). Geografia e Meio Ambiente no Brasil, São Paulo: Editora, Hucitec, 2002. Cap.l, p.46-64.

BRASIL/MMA. Turismo verde. Secretaria de Coordenação da Amazônia/SCA. Brasília, 2002.

CORREAA FILHO, V. Mato Grosso. Campo Grande: Editora, Nacional,1934. 
EGLER, C. A. Questão Regional do Território no Brasil. In: Geografia: Conceitos e Temas. Rio de Janeiro: Editora, Bertrand Brasil, 1995.

GONÇALVES, C. W. P. Formação sócio-espacial e questão ambiental no Brasil. In: Becker, et al,(Org). Geografia e Meio Ambiente no Brasil, São Paulo: Editora, Hucitec, 2002. Cap.IV, p.309-333.

GUIMARÃES, V. A inserção do Território de Figueirão na Bacia Hidrográfica do Alto Taquari. Revista Pantaneira, Aquidauana, v 7, p 50-57, 2005.

MATO GROSSO DO SUL, INSTITUTO DE PLANEJAMENTO DE MATO GROSSO DO SUL. Cenários e Estratégias de Longo Prazo para Mato Grosso do Sul MS 2020. Campo Grande, MS/SEPLANCT/IPLAN, 2003.

MATO GROSSO DO SUL, SEMAC/MS. Dados Estatísticos dos Municípios de MS, 2013. Disponível em: <www1.semac.ms.gov.br/bdeweb/> Acesso em Jul 2013.

MATO GROSSO DO SUL, SEMAC/MS. Política de Desenvolvimento Regional de MS, 2013. Disponível em:<http://www.semac.ms.gov.br/index.php?inside=1\&tp=3\&comp=\&show=2887> Acesso em Jul 2013.

MATO GROSSO DO SUL. PLANO REGIONAL DE DESENVOLVIMENTO SUSTENTÁVEL DA REGIÃO NORTE. Campo Grande, IPLAN/MS/UCDB, 2002.

MATO GROSSO DO SUL. PLANO REGIONAL DE DESENVOLVIMENTO SUSTENTÁVEL DO BOLSÃO. Campo Grande, IPLAN/MS/ UNIDERP, 2003.

OTTMAN, J.A. Marketing verde: desafios e oportunidades para a nova era do marketing. São Paulo: Editora, Makron Books, 1994.

PINHEIRO, M. R. C.; Kury, k. A. Conservação ambiental e conceitos básicos de ecologia. Boletim do Observatório Ambiental Alberto Ribeiro Lamego, Campos dos Goytacazes-RJ,V 2, n. 2, p 15-28, 2008.

QUIRINO, P. B.; ROCHA, M, B. da.; MOURA, L, M, M. Paraíso das Águas... E o lixo?, Fórum Ambiental da Alta Paulista, Tupã, nov, 2013. Disponível em:<

http://amigosdanatureza.org.br/publicacoes/index.php/forum_ambiental/article/view/587/610> acesso em dez 2013.

SANTOS, M.; SILVEIRA, M. L. O Brasil- território e sociedade no início do século XXI. São Paulo: Editora, Record, 2001. Cap.14, p.289-307.

TOMAZ, P.C. A Preservação do Patrimônio Cultural e sua Trajetória no Brasil. Revista de História e Estudos culturais. V 7, n. 2, p 1-12, 2010. 